\title{
In vitro studies of calcium mixed minerals growth in different growth faces and semiconductor laser induced suppression of nuclei strategy
}

\author{
G KANCHANA ${ }^{\dagger}$ and P SUNDARAMOORTHI* \\ Department of Physics, Thiruvalluvar Govt. Arts College, Rasipuram Namakkal 637 401, India \\ ${ }^{\dagger}$ Department of Biochemistry, Muthayammal College of Arts and Science, Rasipuram Namakkal 637 408, India
}

MS received 9 April 2008; revised 28 July 2008

\begin{abstract}
Kidney stone consists of various organic, inorganic and semi organic compounds. Mineral oxalate monohydrate and di-hydrate are the main organic constituents of kidney stones. However, mechanisms leading to the formation of mineral oxalate kidney stones are not clearly understood. The effect of some urinary stone constituents such as ammonium oxalate, calcium citrate, proteins and trace elements were reported by us. The calcium magnesium hydrogen phosphate (CaMHP) crystals were grown in SMS gel medium which provides the necessary kidney stimuli growth medium. The growth processes were done by single diffusion method for different physical and chemical parameters. The $\mathrm{pH}$ range in which $\mathrm{HPO}_{4}^{2-}$ ions dominates were considered which in turn is necessary for the growth of CaMHP crystals. In the present study, calcium magnesium hydrogen phosphate (CaMHP) crystals are grown in three different growth faces to attain the total nucleation reduction. As an extension of this research, many characterization studies have been carried out like XRD, FTIR, TGA, SEM and etching and the results are reported.
\end{abstract}

Keywords. Renal stone; CaMHP; XRD; TGA/DTA; SMS gel.

\section{Introduction}

Strontium hydrogen phosphate (SHP), calcium hydrogen phosphate (CHP) and barium hydrogen phosphate (BHP) are grown in silica gel medium at room temperature (Sundaramoorthi et al 2008). The next approach is to grow mixed crystal in silica gel medium at different environments, which contains two major elements (calcium, phosphate), and one inhibitor (magnesium). CaMHP is a compound crystal, which typically represents the biological crystal formed in the human urinary tracts called renal stones. One can obtain the periodic precipitation, Liesegang rings (Henisch 1986; Sundaramoorthi 2007) of biological crystals named as HAP, brushite, struvite, BMHP, SMHP etc. Calcium is a major component of bones and teeth. It contributes $2 \%$ of the human body weight and $10 \%$ in blood. The function of calcium includes nerves maintenance, blood coagulation, strengthen the muscle contraction, prevent high blood pressure, lower cholesterol and helps to prevent cardiovascular diseases. It also helps to alleviate muscle cramps. Calcium deficiency that is hypocalcaemia will lead to brittle bone and teeth, muscle spasms and over excited nerves. When calcium level increases in the human body fluid (hypercalcaemia), it leads to a lot of side effects. Phosphorus is a mineral that plays

\footnotetext{
*Author for correspondence (sundara78@rediffmail.com; moorthi.sundara@gmail.com)
}

pivotal role in the structure of function of the body. It is essential for the process of bone mineralization and maintains nerve in healthy condition. It constitutes $1 \%$ of the body weight. Vitamin D inhibits the absorption of calcium and phosphorus. When phosphorus level of the body fluid increases, it is called hyperphosphataemia. Magnesium is present in bone and muscle constituting $0.05 \%$ of the human body. It is beneficial in the treatment of neuromuscular disorders. Magnesium and calcium antagonize and collaborate at the same time. Magnesium is necessary for the synthesis of nucleic acid and proteins, while calcium inhibits them. When calcium is deficient, magnesium takes its place in the bone. Magnesium also inhibits increases of cellular calcium level, and maintains normal function of the heart, nerve impulse transmission, control cell membranes and respiratory system. It also relives muscles pain, smoothes muscle contraction, reduces stress and assists in fighting depression. It is protective against cardiovascular diseases and helpful in the treatment of high blood pressure. Alcohol can flush out magnesium and deficiency may lead to ischemic heart disease and convulsion. Magnesium protects the cell from aluminum, mercury, lead, cadmium, beryllium and nickel. Evidence is mounting that low levels of magnesium contributes to the heavy metals deposition in the brain that precedes Parkinson's, multiple sclerosis and Alzheimer's disease. It is probable that low total body magnesium contributes to heavy metal toxicity in children and is a participant in the etiology of learning disorder. Normally, any excess 
magnesium is eliminated in urine but hypermagnesaemia with renal insufficiency may lead to loss of appetite and may be deposited in soft tissues such as kidney, arteries, bone joints, brain, etc. If the mineral level of the body fluid increases, automatic mineral deposition starts leading to the development of renal stones.

\section{Materials and methods}

The dissociation of orthophosphoric acid system can be represented by three-dissociation equilibrium and the presence of various ions at various $\mathrm{pH}$ values are reported (Pecsok et al 1976). Based on these results, the gel $\mathrm{pH}$ in the range from 6-10 has been used (Milwaukee QS-MN $\mathrm{pH}-600$, packet digital $\mathrm{pH}$-meter used for measurements) in which the $\mathrm{HPO}_{4}^{2-}$ ions dominate or exist alone. This decreases the possibility of CaMP crystals occurring during the CaMHP growth. The crystallization apparatus employed were glass test tubes of $25 \mathrm{~mm}$ diameter and $150 \mathrm{~mm}$ long for single diffusion method (SDP). The chemicals used were Excelar-Qualigens (E-Q) AR grade $\mathrm{CaCl}_{2}$, $\mathrm{MgCl}_{2}$ and orthophosphoric acid (Sp.gr.1.75). The SMS gel or water glass was prepared as per the literature (Henisch 1986). One of the reactant orthophosphoric acid was mixed with silica gel at desired gel density and elevated temperatures. After the gel set, the supernatant mixture (calcium chloride + magnesium nitrate) at required mole solutions was slowly added along the walls of the growth columns (test tubes) over the set gels and tightly closed to prevent evaporation. Then the growth systems were allowed to react within the gel medium and the following chemical reaction took place

$$
\begin{aligned}
\left(\mathrm{Ca}^{2+}+\mathrm{Mg}^{2+}\right. & \left.+\left[\mathrm{H}_{3} \mathrm{PO}_{4}^{2-}+\text { gel }\right]\right) \rightarrow \mathrm{CaMgHPO}_{4} \\
& + \text { by products. }
\end{aligned}
$$

\section{Results and discussion}

The reaction starts immediately after the addition of supernatant solutions. But the nucleation was observed only after $12 \mathrm{~h}$ and the growth process took a period of two to three and half months for completion. Leaf shape crystals, fibre and dendrite crystals were observed along with Liesegang rings in the first half of the gel column from the top of the test tube. Some well-developed single and poly crystals were observed in the SDP growth columns after 40 days. The growth processes were allowed for 6 months but the crystal size did not increase. The gel density above $1.06 \mathrm{~g} / \mathrm{cc}$ and with $\mathrm{pH}$ above 8 yielded no crystals but mean time reaction took place. Some of the test tubes of gel density $1.03 \mathrm{~g} / \mathrm{cc}$ with $\mathrm{pH}$ around 6.5 and below 6 were allowed for the reactions to take place. After a period of five months, a less number of nucleation was observed near the bottom and middle of the test tubes. Some of them grew in a needle and well transparent single and platelet crystals. From the investigation, the optimum growth parameters of SDP-CaMHP crystals were identified and reported in table 1 in bold letters. An extension of the reaction period even up to one and half-year did not improve the size of these crystals. The growth columns (SDP) of CaMHP crystals are shown in figures 1-3. Some of the harvested CaMHP crystals are shown in figure 4 . The maximum dimension of the crystals obtained

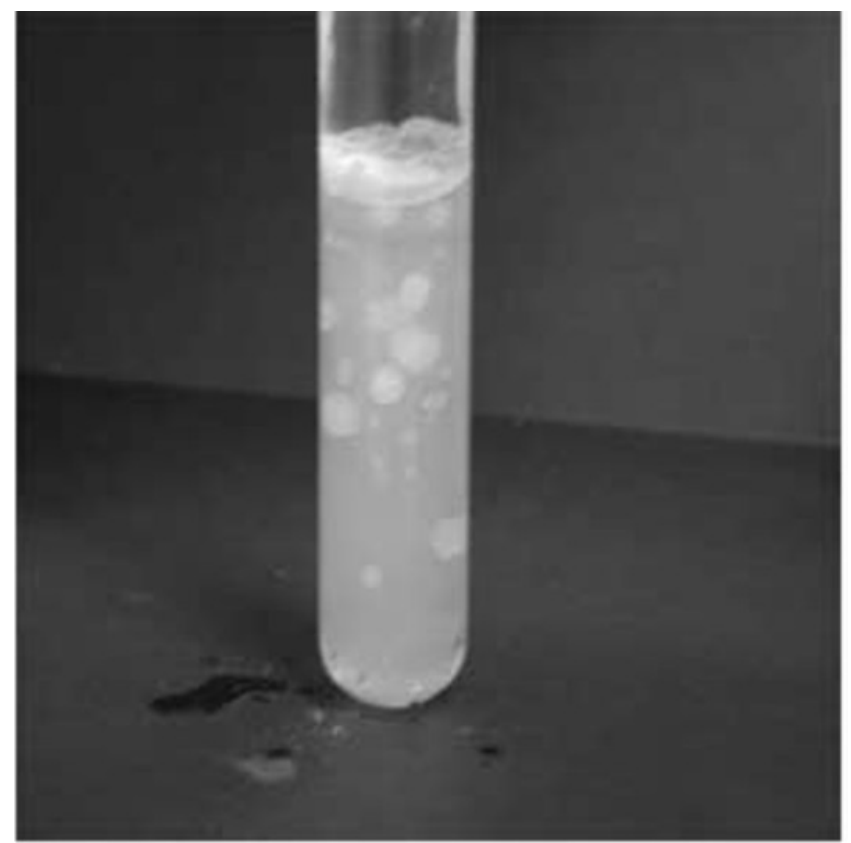

Figure 1. Growth of CaMHP crystals within laboratory environment.

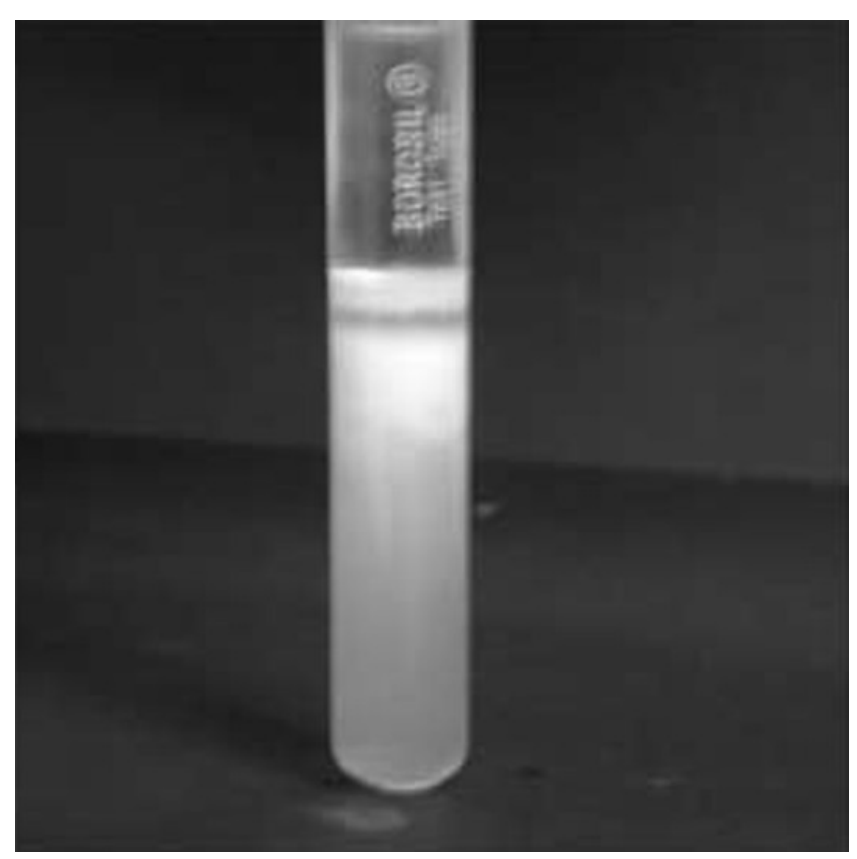

Figure 2. Growth of CaMHP crystals in sunlight. 
Table 1. Growth parameter of CMHP growth process in SDP.

\begin{tabular}{|c|c|c|c|c|c|c|c|}
\hline $\begin{array}{l}\text { Gel density } \\
(\mathrm{g} / \mathrm{cc})\end{array}$ & $\begin{array}{l}\text { Orthophosphoric } \\
\text { concentration }(\mathrm{N})\end{array}$ & $\begin{array}{c}\mathrm{Gel}+\mathrm{H}_{3} \mathrm{PO}_{4} \\
\mathrm{pH} \text { value }\end{array}$ & $\begin{array}{l}\text { Gel setting } \\
\text { time }(\mathrm{h})\end{array}$ & $\begin{array}{c}\text { Supernatant } \\
\text { concentration } \\
\mathrm{CaCl}_{2}+\mathrm{MgCl}_{2}(1 \mathrm{M})\end{array}$ & $\begin{array}{l}\text { Nucleation } \\
\text { observed (h) }\end{array}$ & $\begin{array}{c}\text { Growth } \\
\text { period (days) }\end{array}$ & $\begin{array}{l}\text { Types of crystals } \\
\text { observed and } \\
\text { harvested }\end{array}$ \\
\hline \multirow[t]{8}{*}{1.03} & \multirow[t]{4}{*}{1} & $6 \cdot 4$ & 26 & $1: 1$ & 16 & \multirow[t]{4}{*}{280} & \multirow[t]{4}{*}{ Dendrite crystals } \\
\hline & & $6 \cdot 8$ & 16 & -do- & 17 & & \\
\hline & & $6 \cdot 9$ & 1 & -do- & 32 & & \\
\hline & & $7 \cdot 3$ & 28 & -do- & 89 & & \\
\hline & \multirow[t]{4}{*}{$1 \cdot 5$} & $6 \cdot 6$ & 28 & -do- & 26 & \multirow[t]{4}{*}{290} & \multirow[t]{4}{*}{ Leaf like crystals } \\
\hline & & $6 \cdot 9$ & 2 & -do- & 16 & & \\
\hline & & $7 \cdot 1$ & 3 & -do- & 46 & & \\
\hline & & $8 \cdot 0$ & 46 & - do- & 66 & & \\
\hline \multirow[t]{8}{*}{1.04} & \multirow[t]{4}{*}{1} & $6 \cdot 3$ & 34 & -do- & 12 & \multirow[t]{4}{*}{310} & \multirow[t]{4}{*}{ Single, poly crystals } \\
\hline & & $6 \cdot 8$ & 6 & -do- & 22 & & \\
\hline & & $6 \cdot 9$ & 3 & -do- & 28 & & \\
\hline & & $7 \cdot 4$ & 68 & - do- & 68 & & \\
\hline & \multirow[t]{4}{*}{2} & $6 \cdot 4$ & 44 & -do- & 22 & \multirow[t]{4}{*}{210} & \multirow[t]{4}{*}{$(3 \times 2 \times 3 \mathrm{~mm})$} \\
\hline & & $6 \cdot 7$ & 16 & -do- & 72 & & \\
\hline & & $6 \cdot 8$ & 6 & -do- & 18 & & \\
\hline & & $7 \cdot 5$ & 98 & -do- & 58 & & \\
\hline
\end{tabular}

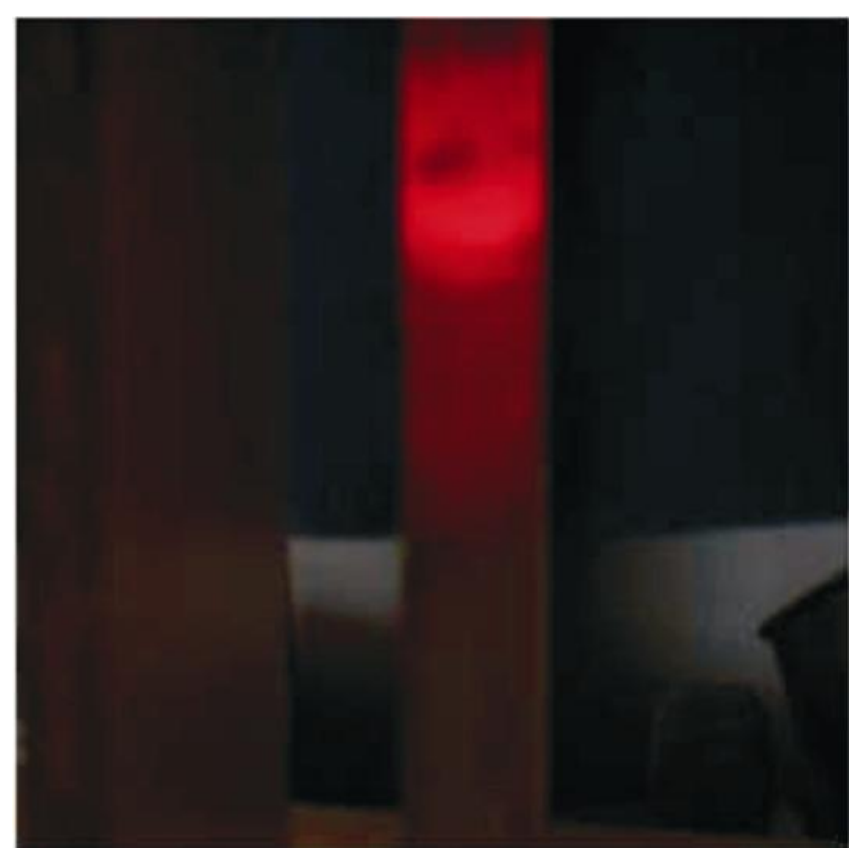

Figure 3. Growth of CaMHP crystals exposed to laser light.

was $3 \times 2 \times 3 \mathrm{~mm}$. In this investigation, fast gel set shows non-transparent gel medium and gives less nucleation and yield.

\subsection{FTIR spectral analysis of CaMHP crystal}

FTIR spectrometer having $\mathrm{KBr}$ pellets sample holder and $\mathrm{KBr}$ detector is used for the analysis. The $\mathrm{KBr}$ pellet samples are used and the absorption frequencies range from $600-4000 \mathrm{~cm}^{-1}$ (Socrater 1980; Tasai 1996). Figure
5 shows the FTIR spectrum of CaMHP crystal. The absorption bands, absorption frequencies and percentage of transmittance are compared with the reported values (Hatscheck 1925; Socrater 1980; Hesse and Bach 1982; Corns 1983; Tasai 1996). The important spectral characteristics of CaMHP is that it shows grouping of five bands at $3477-3047 \mathrm{~cm}^{-1}$ which is due to symmetric and asymmetric $\mathrm{O}-\mathrm{H}$ stretching. The band at $692.02 \mathrm{~cm}^{-1}$ may be due to $\mathrm{O}-\mathrm{H}$ out of plane vibration. Phosphate group usually has absorption frequencies from $1000 \mathrm{~cm}^{-1}$ to $1100 \mathrm{~cm}^{-1}$. These values confirm the presence of grown crystal constituents.

\subsection{Thermogravimetric (TGA and DTA) analysis of CaMHP crystal}

The TGA and DTA of CaMHP crystals are carried out by STA 11500-PLTS instrument. The CaMHP crystal of $7.543 \mathrm{mg}$ sample is taken to the TGA process. The TGA started from room temperature to $900^{\circ} \mathrm{C}$ by heating at a constant rate. Figure 6 shows the TGA-DTA spectrum of CaMHP crystal. The percentage of weights present in the CaMHP sample at a particular temperature is tabulated in table 2. The TGA of CaMHP crystals are anhydrous up to $190^{\circ} \mathrm{C}$. Hereafter the remaining sample is stable up to the end of the analysis.

The expected chemical reactions are given below

$$
\begin{gathered}
\mathrm{CaMgHPO}_{4} \cdot \mathrm{XH}_{2} \mathrm{O} \stackrel{\Delta}{\longrightarrow} \begin{array}{c}
\mathrm{CaMgPO}_{4}+\mathrm{XH}_{2} \mathrm{O} \\
(\text { vapour) },
\end{array} \\
2 \mathrm{CaMgPO}_{4} \stackrel{\boldsymbol{\Delta}}{\longrightarrow} 2 \mathrm{Ca}_{2}, \mathrm{Mg}+2 \mathrm{PO}_{4} \text { (vapour). }
\end{gathered}
$$


Table 2. Thermal analysis of CaMHP crystals.

\begin{tabular}{lcccc}
\hline & \multicolumn{4}{c}{ TGA } \\
\cline { 2 - 5 } $\begin{array}{l}\text { Critical } \\
\text { points }\end{array}$ & $\begin{array}{c}\text { Temperature } \\
\left({ }^{\circ} \mathrm{C}\right)\end{array}$ & $\begin{array}{c}\text { \% of CaMHP } \\
\text { crystal present }\end{array}$ & $\begin{array}{c}\text { Remaining } \\
\text { sample }(\mathrm{mg})\end{array}$ & DTA $\left({ }^{\circ} \mathrm{C}\right)$ \\
\hline 1 & 35 & 100 & 7.543 & 122.94 \\
2 & $122 \cdot 19$ & 104.4 & $7 \cdot 844$ & 170.33 \\
3 & $190 \cdot 69$ & $78 \cdot 8$ & 5.944 & 237.58 \\
4 & 800 & 78.8 & 5.944 & 668.33 \\
5 & 880 & 78.8 & 5.944 & 686.87 \\
\hline
\end{tabular}

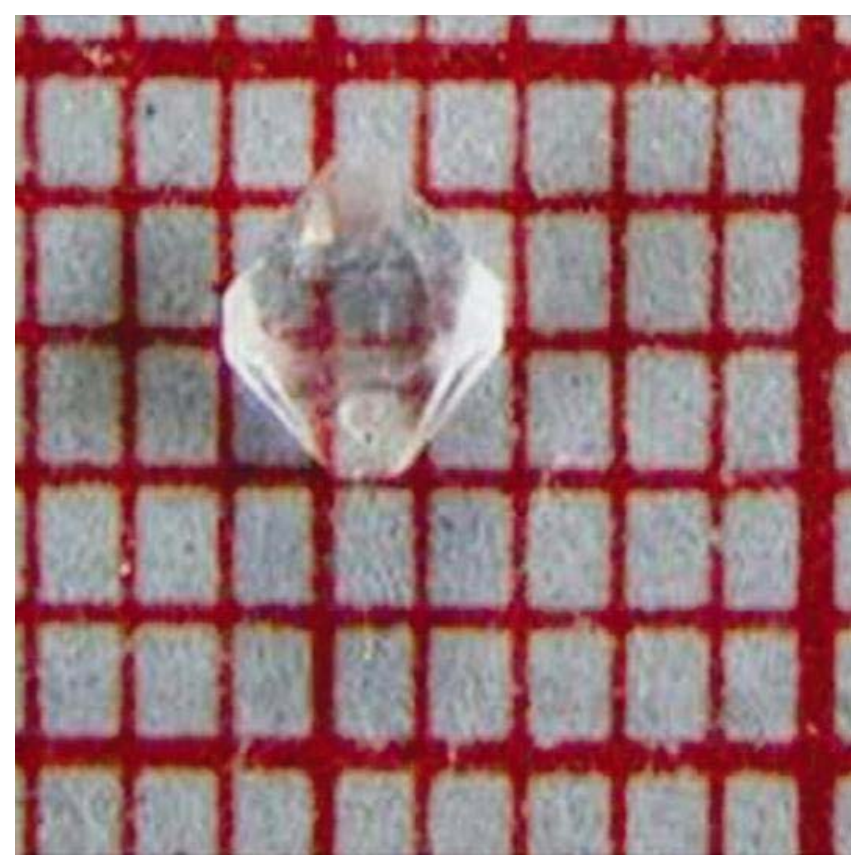

Figure 4. Harvested CaMHP transparent crystal grown from SDP.

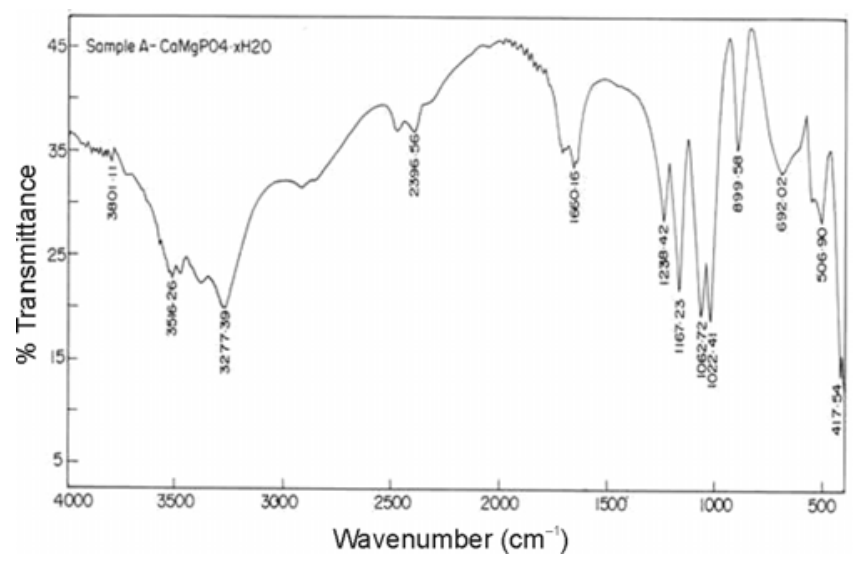

Figure 5. FTIR spectrum of CaMHP crystal.

Calcium and magnesium are stable compounds with respect to the temperature up to $1483^{\circ} \mathrm{C}$ (boiling point of $\mathrm{Ca}, \mathrm{Mg}$ ). About $21.8 \%$ of CaMHP crystals are decomposed and $78.8 \%$ of the sample is stable till the end of the analysis.

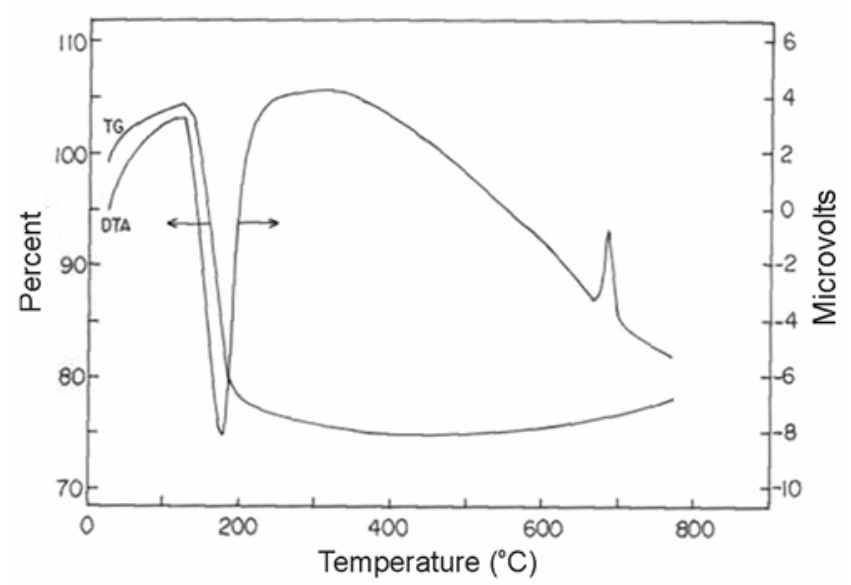

Figure 6. TGA-DTA spectrum of CaMHP crystal.

\subsection{Etching study of CaMHP crystal}

A well-grown CaMHP crystal is immersed in $\mathrm{HCl}$ solution at a desired concentration. The dissolution of CaMHP crystal depends upon the etchant concentration, temperature, crystal morphology, etching time etc (Gilman 1956; Fisher 1957; Gilman et al 1958; New Kirk 1962). The etch pits are shown in figure 7 . The etch pits observed in the photo are knife pits, cone pit, leaf pit and step pits.

\subsection{Scanning electron microscopic study of CaMHP crystal}

A well grown CaMHP single crystal is selected for the investigation of surface morphology by SEM. The SEM photograph is made in the version S-300-I instrument. The sample named VCA-600 is kept in lobe middle; the data size is $640 \times 480 \mu \mathrm{m}$. The minor and major magnification of SEM was about 250 times. SEM acceleration voltage is 25000 volts and the sample is kept in a high vacuum. $18200 \mu \mathrm{m}$ working distance and monochromatic colour mode are employed. $200 \mu \mathrm{m}$ focusing of CaMHP crystal SEM is shown in figure 8 . In the surface analysis of SEM-CaMHP crystal, smooth fine grain boundaries and few valley regions are observed (Gates 1975; Taukamot 1983). 


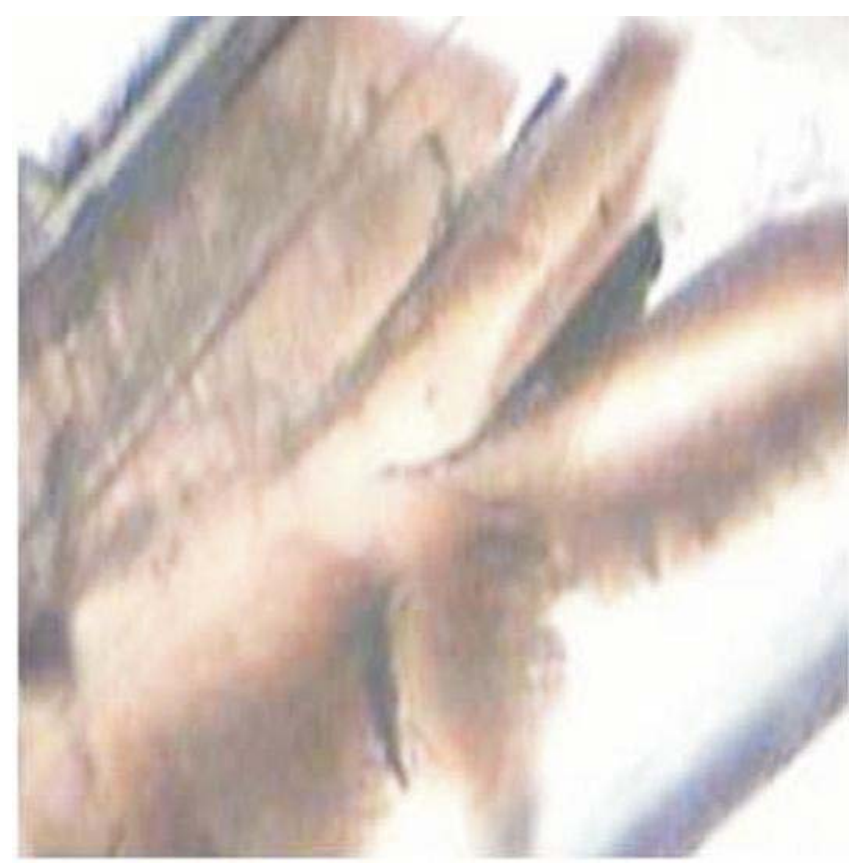

Figure 7. Chemical etching of CaMHP crystal at room temperature, HCL as an etchant, etching time was $6 \mathrm{~min}$ and etchant normality was $1 \mathrm{~N}$

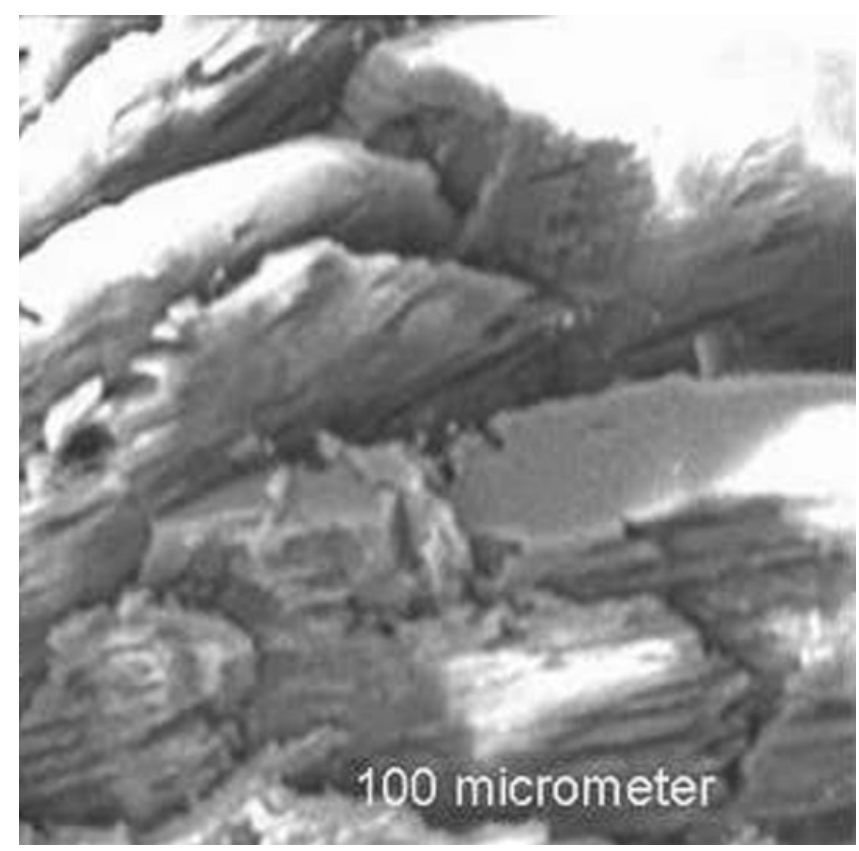

Figure 8. SEM picture of CaMHP crystal.

\subsection{X-ray diffraction of CaMHP crystal}

The single crystal XRD results revealed the crystalline property of grown crystal. The XRD pattern and diffrac- tion indices gives the lattice parameters of CaMHP grown crystal, which are $a=10.0330 \AA, b=10.4067 \AA, c=$ $10.674 \AA, \alpha=90 \cdot 19^{\circ}, \beta=90 \cdot 02^{\circ}, \gamma=90 \cdot 17^{\circ}$. The volume of the unit cell of the CaMHP crystal is $1114.4768(\AA)^{3}$. From this data it is confirmed that CaMHP crystal is triclinic.

\section{Conclusions}

The CaMHP crystals were grown in different growth environments and found the optimum growth parameters. Among these, nucleation was found to be reduced in laser exposed medium due to the inability to attain supersaturation. FTIR-spectrum of CaMHP crystal was recorded and confirms the presence of grown crystal chemical constituents. Chemical etching was done at room temperature, which revealed the grown crystal defects. SEM analysis was also carried out and it shows the surface morphology of CaMHP crystal. The decomposition temperature and percentage of weight loss of the grown crystal are recorded by TGA and DTA analysis. CaMHP lattice parameters are calculated by single crystal XRD analysis and confirmed that the crystal system is triclinic.

\section{References}

Corns C M 1983 J. Ann. Clin. Bio-Chem. 2020

Fisher J C 1957 in Dissolutions and mechanical properties of crystals (New York: John Wiley and Sons)

Gates H C 1975 Thirty years of progress in surface science, in Crystal growth and characterization (North Holland)

Gilman J J 1956 J. Appl. Phys. 271018

Gilman J J, Johnson J and Sears G W 1958 J. Appl. Phys. 29 749

Hatscheck E 1925 J. Kolloid. Z. 37297

Henisch H K 1986 Crystals in gel and Liesegang rings (Cambridge: Cambridge University Press)

Henisch H K and Garcia-Ruiz J M 1986 J. Crystal Growth 75 195,203

Hesse A and Bach D 1982 Stone analysis by infrared spectroscopy, in Urinary stones, clinical and laboratory aspects (Baltimore: Alan Rose, University Park Press) 87105

New Kirk J B 1962 in Direct observation of imperfection in crystals (New York: Inter science Publishers)

Pecsok R L, Shields L D, Cairns T and McWillian I G 1976 Modern methods of chemical analysis (New York: John Wiley Sons Inc.) pp. 438-442

Socrater G 1980 Infrared Cha. Group Freq. (Chichester: John Wiley)

Sundaramoorthi P 2007 Asian J. Chem. 192783

Sundaramoorthi P, Kalainathan S and Kanchana G 2008 Spec. Ch. Acta Part A: Mol. Biomol. Spectrosc. 691154

Tasai Yean Chin 1996 J. Urology 86838

Taukamot K 1983 J. Crystal Growth 61199 